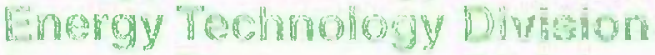
Energy Tochonology brysion Emargy Tochnology Dhwashor

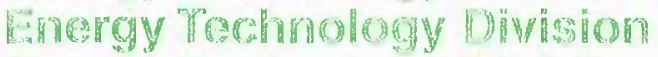
Enargy Techmology Division Fundoy Thennology Divishom Energy Technology Division Energy Technology Division Energy Technology Division Energy Technology Division Energy Technology Division Energy Technology Division

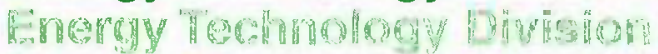
Eneroy Tromology Division Eneray frempology bivhsion? Encroy Taramology divishon Energy Trombratogy Division Encroy "ardmology Division Enoroy rochnology division

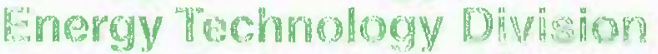
Fmergy formolocy bivision Energy Teabnolooy hivisün

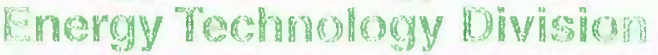
fungroy Treommology divizion Enersy hom hology division farargy Tochantosy Division Ermargy Tachrohogy Divishom Enorgy herbrology Divisaon Eneryy rachnology Division ranargy "lachmology division Enargy bohmolooy division

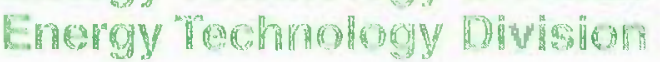

\section{Advanced Sensor Technologies for Next-Generation Vehicles}

\author{
by S. H. Sheen, H. T. Chien, N. Gopalsami, \\ J. A. Jendrzejczyk, and A. C. Raptis
}

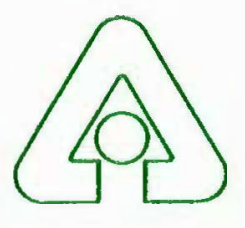

Argonne National Laboratory, Argonne, Illinois 60439 operated by The University of Chicago for the United States Department of Energy under Contract W-31-109-Eng-38
NO ACCESS RESTRICTIONS

This document was reviewed on NoV, 5,2012. for Export Controlled Information (EC) and found to be suitable for unlimited access and reproduction. 
Argonne National Laboratory, with facilities in the states of Illinois and Idaho, is owned by the United States Government and operated by The University of Chicago under the provisions of a contract with the Department of Energy.

\section{DISCLAIMER}

This report was prepared as an account of work sponsored by an agency of the United States Government. Neither the United States Government nor any agency thereof, nor The University of Chicago, nor any of their employees or officers, makes any warranty, express or implied, or assumes any legal liability or responsibility for the accuracy, completeness, or usefulness of any information, apparatus, product, or process disclosed, or represents that its use would not infringe privately owned rights. Reference herein to any specific commercial product, process, or service by trade name, trademark, manufacturer, or otherwise, does not necessarily constitute or imply its endorsement, recommendation, or favoring by the United States Government or any agency thereof. The views and opinions of document authors expressed herein do not necessarily state or reflect those of the United States Government or any agency thereof, Argonne National Laboratory, or The University of Chicago.

Available electronically at http://www.doe.gov/bridge

Available for a processing fee to U.S. Department of Energy and its contractors, in paper, from:

U.S. Department of Energy

Office of Scientific and Technical Information

P.O. Box 62

Oak Ridge, TN 37831-0062

phone: (865) 576-8401

fax: (865) 576-5728

email: reports@;adonis.osti.gov 


\section{ARGONNE NATIONAL LABORATORY \\ 9700 South Cass Avenue \\ Argonne, Illinois 60439}

ANL-01/27

\section{ADVANCED SENSOR TECHNOLOGIES FOR NEXT-GENERATION VEHICLES}

\section{by}

S. H. Sheen, H. T. Chien, N. Gopalsami, J. A. Jendrzejczyk, and A. C. Raptis

Sensors, Instrumentation, and Nondestructive Evaluation (SI\&NDE) Section

Energy Technology Division

November 2001

Work Sponsored by

U.S. DEPARTMENT OF ENERGY

Office of Transportation

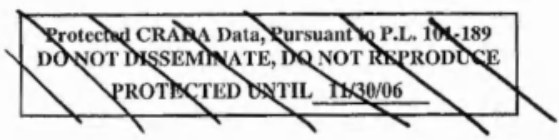





\section{CONTENTS}

ABSTRACT

1.0 INTRODUCTION

2.0 DESCRIPTION OF SENSOR TECHNOLOGIES .

2.1 Surface Acoustic-Wave Sensors...

2.1.1 SAW Chemical Sensor ........................................................................ 2

2.1.2 FPW Chemical Sensor.................................................................. 4

2.2 Microwave Cavity Sensor .......................................................................... 6

2.3 Ion-Mobility Spectrometry Sensors ....................................................... 7

3.0 LABORATORY TEST RESULTS .............................................................. 9

3.1 Surface Acoustic-Wave Sensors.............................................................. 9

3.2 Microwave Cavity Sensor .................................................................. 12

4.0 NONRADIOACTIVE ION-MOBILITY SPECTROMETRY SENSOR ................. 14

4.1 IMS Sensor Design ................................................................................ 15

4.2 Laboratory Tests ........................................................................... 16

4.3 Results and Discussion................................................................... 18

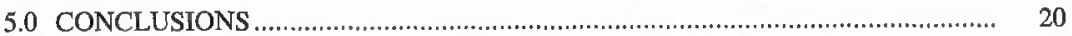

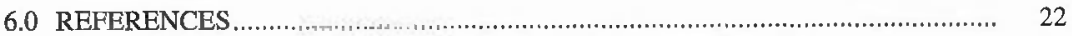




\section{FIGURES}

1. Basic design of a SAW chemical sensor .................................

2. Basic design of a FPW chemical sensor ............................................... 5

3. Diagram of microwave cavity built at ANL ............................................. 7

4. Frequency shifts of SAW sensor with Carbowax coating for various flow rates of nitrogen gas

5. Frequency shifts of SAW sensor with Carbowax coating during cycling for flow rate of $200 \mathrm{cc} / \mathrm{min}$ of nitrogen and $50 \mathrm{cc} / \mathrm{min}$ of the test gas.....

6. Frequency shifts of the SAW sensor with Carbowax coating for flow rate of $50 \mathrm{cc} / \mathrm{min}$ of nitrogen mixed with $50 \mathrm{cc} / \mathrm{min}$ of the test gas

7. Equipment layout for testing $\mathrm{MW}$ cavity sensor ....................................... 11

8. Sample dielectric data from lab experiments ......................................... 12

9. $0.2 \%$ propylene at different frequencies. ............................................... 12

10. Sensitivity test using $102 \mathrm{ppm}$ formaldehyde ............................................ 13

11. Basic design of ion-mobility spectrometer .............................................. 14

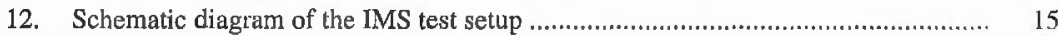

13. Negative $\mathrm{NO}_{2}$ ion spectra at different gas flow rates .................................... 16

14. Negative $\mathrm{NO}_{2}$ ion spectra produced by corona and spark discharges .................... 16

15. Negative $\mathrm{NO}_{2}$ ion peaks produced by corona discharge ionization for four

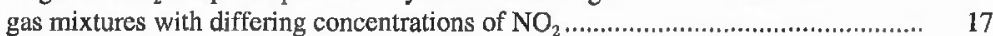

16. Negative $\mathrm{NO}_{2}$ spectra produced by spark discharge ionization for three $\mathrm{NO}_{2}$ concentrations expressed in terms of carrier/sample gas ratio.

17. Peak amplitude vs. $\mathrm{NO}_{2}$ concentration, measured with dry nitrogen and 2-nA/V sensitivity

18. Peak amplitude vs. $\mathrm{NO}_{2}$ concentration measured with carrier gas and $5-\Pi \mathrm{A} / \mathrm{V}$ sensitivity

19. $\mathrm{NO}_{2}$ ion spectra of $\mathrm{NO}_{2}$ / carrier-gas mixtures with different water vapor concentrations

20. Negative $\mathrm{NO}_{2}$ ion peaks detected by controlling the carrier gas temperature

21. Amplitude of negative $\mathrm{NO}_{2}$ ion peak vs. gas concentration with temperature controlled at $0^{\circ} \mathrm{C}(2 \mathrm{nA} / \mathrm{V}$ sensitivity) 


\section{TABLES}

1. Commercially available coatings for SAW chemical sensors, their target gases, and detection limits

2. Detection sensitivities of three acoustic chemical-sensing technologies ................. 5

3. Design parameters and operating conditions of the IMS sensor 


\section{ACKNOWLEDGMENTS}

This work was supported by the U.S. Department of Energy (DOE) Office of Transportation, as part of a Cooperative Research and Development Agrcement (CRADA) with the DOE. The authors thank R. Sullivan of DOE, J. H. Visser and S. G. Ejakov of Ford Research Laboratory, E. Gonze and S. Schmieg of General Motors, and A. Lee of DaimlerChrysler for their support, guidance. and advice. 


\title{
ADVANCED SENSOR TECHNOLOGIES FOR NEXT-GENERATION VEHICLES
}

by

\author{
S. H. Sheen, H. T. Chien, N. Gopalsami, J. A. Jendrzejczyk, and A. C. Raptis
}

\begin{abstract}
This report summarizes the development of automobile emissions sensors at Argonne National Laboratory. Three types of sensor technologies, i.e., ultrasound, microwave, and ion-mobility spectrometry (IMS), were evaluated for engine-out emissions monitoring. Two acoustic sensor technologies, i.e., surface acoustic wave and flexural plate wave, were evaluated for detection of hydrocarbons. The microwave technique involves a cavity design and measures the shifts in resonance frequency that are a result of the presence of trace organic compounds. The IMS technique was chosen for further development into a practical emissions sensor. An IMS sensor with a radioactive ${ }^{63} \mathrm{Ni}$ ion source was initially developed and applied to measurement of hydrocarbons and $\mathrm{NO}_{\mathrm{x}}$ emissions. For practical applications, corona and spark discharge ion sources were later developed and applied to $\mathrm{NO}_{\mathrm{x}}$ emission measurement. The concentrations of $\mathrm{NO}_{2}$ in dry nitrogen and in a typical exhaust gas mixture are presented. The sensor response to moisture was evaluated, and a cooling method to control the moisture content in the gas stream was examined. Results show that the moisture effect can be reduced by using a thermoelectric cold plate. The design and performance of a laboratory prototype sensor are described.
\end{abstract}

\subsection{INTRODUCTION}

This is the final report of a project funded by the Department of Energy (DOE), Office of Transportation under a Cooperative Research and Development Agreement (CRADA) established between Argonne National Laboratory (ANL) and the Low Emissions Technologies Research and Development Partnership (LEP) formed under the United States Council on Automobile Research (USCAR). The objective of this project was to develop a sensor system capable of monitoring engine-out emissions from an internal combustion engine. Designed for a low-emission vehicle, the sensor system would monitor the performance of the catalytic converter system to ensure compliance with On-Board Diagnostics II regulations as defined by the California Air Resource Board and the U.S. Environmental Protection Agency. These sensors directly support both Phase 2 and Phase 3 objectives of the Partnership for a New Generation of Vehicles (PNGV) by providing (a) the capability to monitor the hydrocarbon (HC) emissions from pre- and postcatalytic converters, as required for Phase 2, and (b) the ability to monitor $\mathrm{NO}_{\mathrm{x}}$ emissions in the compression-ignition direct-injection (CIDI) combustion engines in support of Phase 3 objectives. Furthermore, these sensors may also be used as feedback control for the fuel control system of a low-emission vehicle.

Three sensor technologies, i.e., ultrasound, microwave (MW), and ion-mobility spectrometry (IMS), were examined under this project. Ultrasonic techniques are based on microbalance sensor technology, which includes the use of surface acoustic wave (SAW) and flexural-plate-

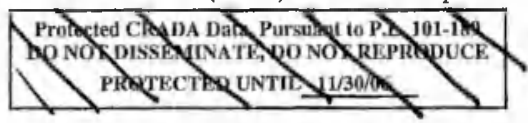


wave (FPW) sensors, which rely on a chemically selective coating deposited on, respectively, a piezoelectric crystal and a thin plate in which Lamb waves are propagating. The microwave technigue involves a cavity design and measures the shifts in resonance frequency that are a result of the presence of trace organic compounds. Both the ultrasonic and the MW techniques were tested only for sensing HC. The IMS technique, which is similar to time-of-flight (TOF) mass spectrometry but operates under ambient conditions, detects trace gases by first ionizing the gas molecules and then accelerating the gas ions in a drift tube to a charge detector. Both TOF of the ions and ion current are measured; the former determines the gas species, the latter, quantifies them. An IMS with a $\beta$-emitting ${ }^{63} \mathrm{Ni}$ source was initially developed to detect HCs and later applied to detect $\mathrm{NO}_{x}$. Because of the safety concerns about the use of a radioactive ion source, a nonradioactive ion source, such as a corona discharge ion source, was developed. In this report we first describe the baseline principles of the technologies and then summarize test results obtained with laboratory setups.

\subsection{DESCRIPTION OF SENSOR TECHNOLOGIES}

\subsection{Surface Acoustic-Wave Sensors}

The goal of this task is to develop tailpipe or engine-out emission sensors based on ultrasonic techniques. The sensors will be used to monitor the performance of catalytic converters; thus, they must be able to survive in high-temperature environments and be chemically sensitive to the targeted gases, including $\mathrm{NO}_{\mathrm{x}}$ and $\mathrm{HCs}$. The primary ultrasonic technique that we examined was the SAW chemical sensing method. However, we also evaluated a technique that is based on FPW chemical sensing because both of these methods share the same sensing arrangement, the use of a chemical-sensitive coating.

\subsubsection{SAW Chemical Sensor}

Since 1971, when White and Voltmer [1,2] first reported the generation of elastic waves in piezoelectric materials by using lithographically patterned microelectrodes, many chemical and physical sensors that rely on the Rayleigh SAW techniques have been developed and applied to environmental monitoring, clinical analysis, and industrial process control. The first SAW device for the detection of chemical vapor was developed by Wohltjen [3] in 1979. Since then, the use of SAW devices as chemical sensors for various applications has increased. The growing interest in these devices is due to their many attractive features, which include high sensitivity and small size.

SAW devices are arranged in a delay line configuration that consists of two sets of lithographically patterned interdigital electrodes (IDTs) deposited onto the surface of an optically smooth piezoelectric substrate. One set of IDTs generates a high-frequency Rayleigh wave that propagates along the device surface and is detected by the second set of IDTs. When the SAW device is used as the feedback element in an oscillator circuit, the frequency of the circuit is linearly related to the surface wave velocity that is strongly perturbed by surface mass loading.

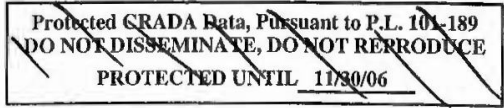


A SAW chemical sensor requires a chemically sensitive coating applied to the substrate surface between the two IDTs. Figure 1 shows the basic design of a SAW chemical sensor. When vapors sorb into the coating, an incremental change occurs in the coating density. Variations in the density, viscosity, and elastic properties of the coating will affect the phase, amplitude, and velocity of the surface acoustic wave. For SAW chemical sensors, it is the density or mass loading change that makes the chemical detection possible. Theoretically, the frequency change, $\Delta f$, of the SAW oscillator can be related to the coating density, $\rho$, by the following relationship:

$$
\Delta f=\left(k_{1}+k_{2}\right) f^{2} h \rho,
$$

where $k_{1}$ and $k_{2}$ are material constants for the piezoelectric substrate, $f$ is the unperturbed resonant frequency of the SAW oscillator, and $h$ is the coating thickness.

Equation 1 indicates that the frequency change is linearly proportional to density, and the detection sensitivity strongly depends on the operating frequency. The materiai constants for the commonly used ST-quartz piezoelectric SAW devices are $-8.7 \times 10^{-8}$ and $-3.9 \times 10^{-8} \mathrm{~m}^{2} \mathrm{~s} / \mathrm{kg}$. The product of coating thickness and density is equivalent to the mass per unit area present on the device surface. The typical operating frequency is $\approx 100 \mathrm{MHz}$, which gives a detection sensitivity of ppb. Experimental studies have demonstrated that a SAW device with an active surface area of $\approx 8 \mathrm{~mm}^{2}$ produces a frequency shift of $\approx 365 \mathrm{~Hz}$ when perturbed by a surface mass loading of $1 \mathrm{ng}$, with a typical frequency noise level of $<16 \mathrm{~Hz}$ over a 1 -s measurement interval. Thus, the signal-to-noise ratio is $\approx 23: 1$ for a 1 -ng mass change.

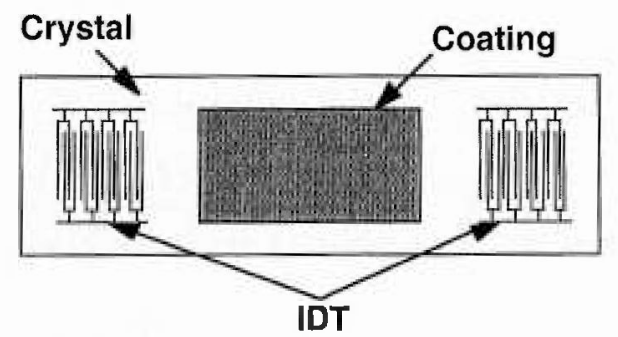

Fig. 1. Basic design of SAW chemical sensor.

The sensitivity and selectivity of a SAW chemical sensor are controlled by the coating material deposited on the surface of the device. The coating preferentially concentrates the vapor of interest onto the surface of the device through physical (e.g., adsorption or absorption) or chemical interactions. Thus, both sensitivity and selectivity are determined by the physical and chemical properties of both the coating and the vapor. Furthermore, selection of coatings must consider both specificity and reversibility, which are inversely related. At present, coatings that have been developed are primarily for gases of environmental interest. Table 1 lists some commercially available coatings.

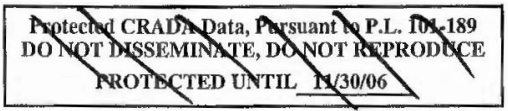


Table 1. Commercially available coatings for SAW chemical sensors, their target gases, and detection limits ${ }^{a}$

\begin{tabular}{|c|c|c|}
\hline Coating & Target Gas & Detection Limit \\
\hline Ethyl cellulose & $\begin{array}{l}\text { Aromatics } \\
\text { Halocarbons }\end{array}$ & $\begin{array}{c}10 \mathrm{mg} / \mathrm{m}^{3} \\
200 \mathrm{mg} / \mathrm{m}^{3}\end{array}$ \\
\hline Poly(ethyleneimine) & $\begin{array}{l}\text { Water } \\
\text { Alcohols }\end{array}$ & $\begin{array}{l}10 \mathrm{mg} / \mathrm{m}^{3} \\
25 \mathrm{mg} / \mathrm{m}^{3}\end{array}$ \\
\hline Poly(isobutylene) & Aromatic hydrocarbons & $50 \mathrm{mg} / \mathrm{m}^{3}$ \\
\hline Fluoropolyol & Nerve agents and simulants & $0.1-1 \mathrm{mg} / \mathrm{m}^{3}$ \\
\hline Tenax GC & Various organic solvents & $25 \mathrm{mg} / \mathrm{m}^{3}$ \\
\hline $\begin{array}{c}\text { M-Phthalocyanine } \\
(\mathrm{M}=\mathrm{Cu} . \mathrm{Pb})\end{array}$ & $\mathrm{NO}_{2}$ & $0.25 \mathrm{ppm}$ \\
\hline $\begin{array}{l}\text { N,N,N'N' Tetrakis } \\
\text { (2-hydroxy ethyl) } \\
\text { ethylenediamine }\end{array}$ & Sulfur Dioxide & $0.1 \mathrm{ppm}$ \\
\hline $\mathrm{WO}_{3}$ & Hydrogen Sulfide & $0.05 \mathrm{ppm}$ \\
\hline
\end{tabular}

Provided by H. Wohltjen of Microsensor Systems Inc., Bowling Green, KY.

\subsubsection{FPW Chemical Sensors}

The difference between SAW and FPW chemical sensors is the type of wave being monitored; the former analyzes the Rayleigh wave, the latter, the Lamb waves. Figure 2 shows the basic design of a FPW chemical sensor. It consists of a thin plate (e.g., silicon nitride) bonded to a chemical-sensitive coating on one side and attached to transducers (IDTs or piezoelectric films) on the other side. In practice, the thin plate is a composite diaphragm of silicon nitride, metal, and piezoelectric zinc oxide. During operation, ultrasonic waves are generated by one transducer, propagate in the plate, and are detected by the other transducer. The phase velocity of FPWs (or Lamb waves) is measured, and its changes are related to the amount of gases absorbed by the coating. The phase velocity $V_{P}$ of the zeroth-order Lamb wave is

$$
V_{p}=(2 \pi / \lambda) \sqrt{ } C /(m+\Delta m),
$$

where $C$ is the effective plate stiffness, $\lambda$ is the FPW wavelength, $m$ is the unloaded mass per unit area of the plate, and $\Delta m$ represents the mass of absorbed gases. The detection sensitivity of the FPW technique was analyzed [4] and compared with SAW and bulk-wave techniques. The results of the comparison are listed in Table 2. The chief advantage of the FPW technique is high sensitivity to added mass at a low operating frequency. Detection in the ppb range was achieved [5]. 


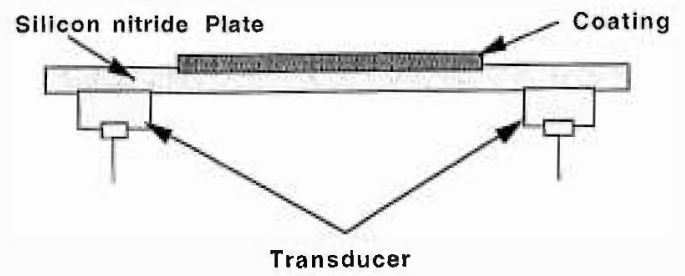

Fig. 2. Basic design of FPW chemical sensor.

Table 2. Detection sensitivities of three acoustic chemical-sensing technologies ${ }^{\mathrm{a}}$

\begin{tabular}{|c|c|c|c|c|c|}
\hline \multirow[b]{2}{*}{ Sensor } & \multirow{2}{*}{$\begin{array}{l}\text { Theoretical } \\
\text { Sensitivity }\end{array}$} & \multirow{2}{*}{$\begin{array}{c}\text { Device } \\
\text { Description }\end{array}$} & \multirow{2}{*}{$\begin{array}{l}\text { Operating } \\
\text { Frequency } \\
\text { (MHz) }\end{array}$} & \multicolumn{2}{|c|}{ Sensitivity $\left(\mathrm{cm}^{2} / \mathrm{g}\right)$} \\
\hline & & & & Experimental & Calculated \\
\hline Bulk wave & $\begin{array}{l}-2 / \lambda \rho \text { or } \\
-n / \lambda \rho\end{array}$ & $\begin{array}{l}\mathrm{AT} \text {-cut quartz } \\
\text { resonator }\end{array}$ & 6 & -14 & -14 \\
\hline SAW & $-\mathbf{K}(\sigma) / \lambda \rho$ & $\begin{array}{l}\text { ST-cut SAW } \\
\text { delay line }\end{array}$ & 31 & -17 & -42 \\
\hline SAW & $-K(\sigma) / \lambda \rho$ & $\begin{array}{l}\text { ST-cut SAW } \\
\text { delay line }\end{array}$ & 112 & -91 & -151 \\
\hline FPW & $-1 / 2 \rho d$ & $\begin{array}{l}\mathrm{ZnO} \text {-on-silicon } \\
\text { nitride flexural- } \\
\text { mode delay line }\end{array}$ & 4.7 & -442 & -450 \\
\hline FPW & $-1 / 2 \rho d$ & $\begin{array}{l}\text { ZnO-on-silicon } \\
\text { nitride flexural- } \\
\text { mode delay line }\end{array}$ & 2.6 & -990 & -951 \\
\hline
\end{tabular}

"Adopted from Ref. 5, $\lambda=$ wavelength, $\rho=$ substrate density, $n=$ integer, $d=$ substrate thickness, $K(\sigma)=$ a parameter that is a function of Poisson's ratio $\sigma$.

\subsection{Microwave Cavity Sensors}

Microwave/millimeter wave (MW/mmw) spectroscopy provides $100 \%$ species selectivity under partial vacuum. It is sensitive to polar gases such as $\mathrm{CO}$, NO, and oxygenated HCs (aldehydes, alcohols, and ketones). Furthermore, it is moderately sensitive to several other HCs (propylene, 1,3 butadiene, xylene, toluene, butene, etc.). One of the primary concerns of this technology is that water or $\mathrm{CO}_{2}$ may interfere with the gas spectra. Thus one must choose a frequency range 
that is outside of water's $22 \mathrm{GHz}$ line. In the $8-17 \mathrm{GHz}$ range, there is no interference from water vapor, $\mathrm{CO}_{2}$, and methane.

Modeling of the absorption spectra at various pressures indicated that moderate vacuum would help improve our specificity. Most spectra are distinguishable at $\approx 100$ Torr. Our use of the complex dielectric constant provides more data with which to identify a gas, thus reducing the limitation imposed by the specificity requirement. Using these parameters, we designed a circular resonating cavity, a diagram of which is shown in Fig. 3. The basic idea was to adjust the resonance frequency and thereby map the absorption spectra. The resonance frequency can be changed by varying the height, $h$, or the radius, $a$; the theoretical relationships of resonance frequencies as a function of cavity radius and height for TE and TM modes, respectively. are

$$
\begin{aligned}
& \left(f_{r}\right)_{m n p}=\frac{1}{2 \pi \sqrt{\mu \varepsilon}} \sqrt{\left(\frac{\chi_{m n}^{\prime}}{a}\right)^{2}+\left(\frac{p \pi}{h}\right)^{2}} \\
& m=0,1,2,3, \ldots ; n=1,2,3, \ldots ; p=1,2,3, \ldots \\
& \left(f_{r}\right)_{m n n}=\frac{1}{2 \pi \sqrt{\mu \varepsilon}} \sqrt{\left(\frac{\chi_{m n}}{a}\right)^{2}+\left(\frac{p \pi}{h}\right)^{2}} \\
& m=0,1,2,3, \ldots ; n=1,2,3, \ldots ; p=0,1,2,3 \ldots
\end{aligned}
$$

where $\chi_{m n}$ represents the $n$th zero of the derivative of the Bessel function, $J_{m^{\prime}}$ of the first kind of order $m$. An adjustable cavity can therefore be used to scan a wide range of frequencies solely with the $T E_{0 I I}$ resonance line.

For practical purposes, our cavity was designed with a $2-\mathrm{cm}$ radius and a $6-\mathrm{cm}$ height, adjustable by tuning a movable end on the cavity. In application environments, this can be scaled down to smaller sizes. Several of these devices can be permanently set at exact frequencies to look for specific molecules, or a single cavity can be adjusted as we did in our laboratory experiments. 


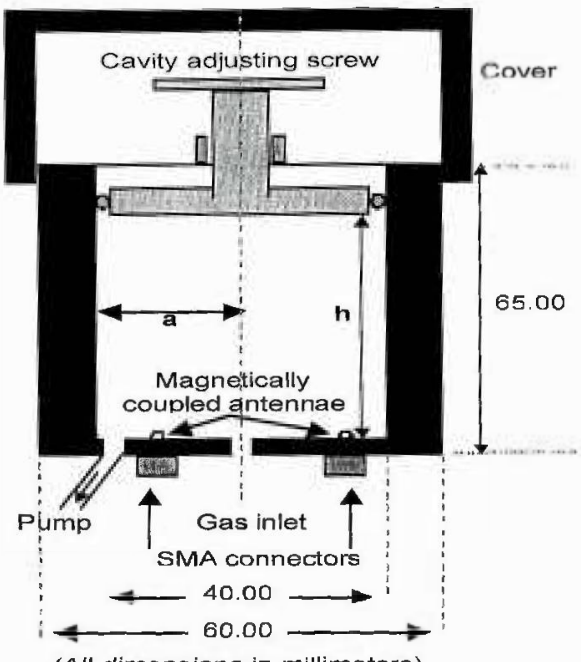

(All dimensions in millimeters)

Fig. 3. Diagram of microwave cavity built at ANL.

\subsection{Ion-Mobility Spectrometry Sensor}

The basic IMS sensor consists of an ion source, a drift tube, and an ion detector. The ion source ionizes gas molecules by either direct electron bombardment or ion-molecule reactions. Product ions are then extracted into the drift tube and move down the tube to the detector in a uniform electric field. The velocity of the ion drift, a measurable quantity from IMS data, is influenced by both the applied electrical field, $E$, and the ion concentration gradient $(\partial n / \partial x)[6,7]$. To include only the linear terms, the drift velocity is given by the equation

$$
V=K E-\frac{D}{n}\left(\frac{\partial n}{\partial x}\right)
$$

where $n$ is ion concentration; $D$, the diffusion coefficient; and $K$, the ion mobility. The diffusion term is generally very small, especially under ambient conditions. Thus the ion drift velocity provides a direct measure of ion mobility. Based on Eq. 5, the electric force may be balanced by the diffusion force that is needed to reach an equilibrium at which $V=0$. Assuming that the ion concentration follows a Boltzmann distribution, one can obtain the Nernst-Einstein relationship that relates the mobility with the ion diffusion coefficient, given as

$$
K=q D / k T
$$

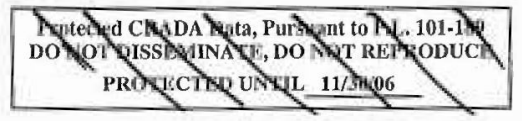


where $q$ is the charge and $k$, the Boltzmann constant. When the ion motion is not in equilibrium, the dominating effect is ion-neutral collisions, and the mobility is given by

$$
K=\left(\frac{q}{n}\right)^{1 / 2}\left(\frac{1}{3 \mu T_{e f f}}\right)^{1 / 2}\left[\frac{1}{\Omega\left(T_{e f f}\right)}\right],
$$

where $\mu$ is the reduced mass of ion and buffer gas, $T_{e f f}=T+M V^{2} / 3 k$ ( $M$ is molecular weight of the buffer gas), and $\Omega\left(T_{e f f}\right)$ is the total scattering cross section. Conceptually, ions that differ exhibit differing mobilities in the same medium. But, just as mass spectrometry determines the charge/mass ratio, the ion mobility determines the value of $q / \mu^{1 / 2} \Omega$. For heavy ions, $\mu$ is nearly equal to the mass of the neutral molecule (e.g., nitrogen), and $\Omega$ essentially measures the average cross-sectional area of the ion or the ion size. On the other hand, for a series of atomic ions in the same neutral gas, $\Omega$ is nearly constant, and the mobility is determined by the reduced mass, assuming that $q$ is fixed. In practice, the buffer gas is a gas mixture. The mobility of an ion in a gas mixture can be approximated by Blanc's law [8], given as

$$
\frac{1}{K}=\sum_{j} \frac{X_{j}}{K_{j}}
$$

where $X_{I}$ is the mole fraction of the $j$ th gas.

In principle, if all ion-molecule interactions that occur in the drift tube are known, the ionmobility spectrum gives a fingerprint of the ions present. However, in practice, the peak position and shape depend on the composition of the gas mixture, temperature, and flow rate. Therefore, each spectrum may need a set of calibration data for its application in identifying ions. For quantitative measurements, the peak amplitude may be used.

Under this CRADA project, we initially were directed to develop an IMS sensor for detecting HCs. A prototype IMS that used a ${ }^{63} \mathrm{Ni} \beta$ source was designed and tested for its capability to detect various HCs in a typical gasoline mixture [9]. To detect HCs, IMS was operated in positive-ion mode. Laboratory test results showed that the sensitivity of the IMS sensor to the tested HCs was adequate. Various $\mathrm{HCs}$ seemed to show drift times that differed, but the drift time was also concentration dependent, particularly, for polar molecules. Significant interference from water vapor was also observed. Later, the project was redirected to detect $\mathrm{NO}_{\mathrm{x}}$ by IMS. We modified the IMS prototype to operate in negative-ion mode. Results showed that IMS was highly sensitive in detecting $\mathrm{NO}$ and $\mathrm{NO}_{2}$, and both the drift time and amplitude were functions of $\mathrm{NO}_{\mathrm{x}}$ concentration [10].

\subsection{LABORATORY TEST RESULTS}

In this section, we present laboratory test results of the three technologies. The results summarize the feasibility studies of the technologies applied to detect auto emissions. Based on the practical requirements of a tail-pipe exhaust sensor, further development beyond the feasibility study was discontinued for both SAW and MW cavity sensors. Development of the IMS sensor for $\mathrm{NO}_{x}$ detection was continued, with emphasis on evaluation of a nonradioactive ion source.

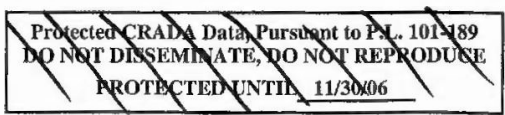




\subsection{Surface Acoustic-Wave Sensors}

Both SAW and FPW chemical sensors require chemical-selective coatings for gas detection. Therefore, the focus of the project is to identify and evaluate coating materials for detecting HCs and $\mathrm{NO}_{X}$ in the tail pipe environment. A literature survey of coating materials was initially conducted. To date, development has been mainly in detection of $\mathrm{NO}_{\mathrm{x}}$; two types of hightemperature coating, $\mathrm{M}$-phthalocyanine $(\mathrm{M}=\mathrm{Cu}, \mathrm{Pb})$ and $\mathrm{WO}_{3}$, have shown high sensitivity in detecting $\mathrm{NO}_{2}$. But, the selection of coatings for detecting HCs has not been clearly defined. Because detection of $\mathrm{HC}$ emissions was stressed in this project, organic polymers were selected for initial evaluation of SAW sensors. The coating materials selected for $\mathrm{HCs}$ must be nonvolatile, exhibit few hysteresis and stiffness effects, and interact with HCs via the induceddipole effect. Three coating materials, poly(isobutylene), poly(epichlorhydrin), and Carbowax $20 \mathrm{M}$, were identified.

SAW devices that operate at $\approx 250 \mathrm{MHz}$ and are coated with the identified polymers were obtained from Microsensor Systems Inc. (Bowling Green, KY). Sensors were tested with a gas mixture that was composed of $97.99 \% \mathrm{~N}_{2}, 0.4 \% \mathrm{CO}, 1.3 \% \mathrm{H}_{2}, 0.28 \% \mathrm{O}_{2}, 100 \mathrm{ppm}$ propane, and $200 \mathrm{ppm}$ propylene.

Figure 4 shows the shifts in the resonance frequency of a SAW sensor with Carbowax coating as the flow rate, of nitrogen gas is varied. Clearly, the frequency change is proportional to the flow rate and significant baseline drift occurs. Figure 5 shows the frequency shifts of the same sensor under a flow rate of $200 \mathrm{cc} / \mathrm{min}$ of nitrogen mixed with $50 \mathrm{cc} / \mathrm{min}$ of the test gas. The $300 \mathrm{ppm}$ HCs in the test gas did not show significant change in the output frequency shift; thus, the sensitivity of the sensor was poor in detecting HCs. However, when we reduced the carrier nitrogen gas, the sensor showed measurable response on the test gas, as shown in Fig. 6 . Similar results were obtained for the other two coatings. Because polymer coatings generally cannot survive high-temperature environments, further development of the SAW/FPW sensors was discontinued.

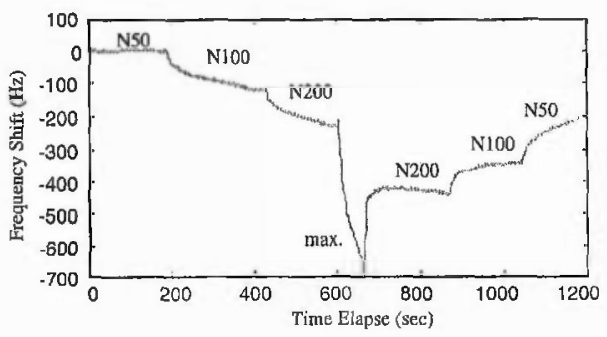

Fig. 4. Frequency shifts of SAW sensor with Carbowax coating for various flow rates of nitrogen gas. (Rates in cc/min.)

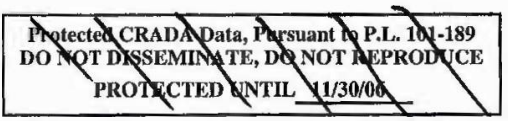




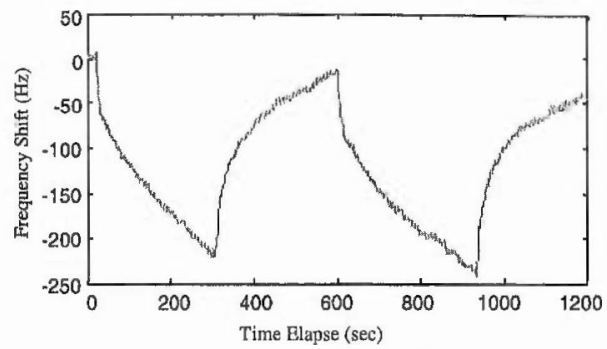

Fig. 5. Frequency shifts of SAW sensor with Carbowax coating during cycling for flow rate of $200 \mathrm{cc} / \mathrm{min}$ of nitrogen and $50 \mathrm{cc} / \mathrm{min}$ of test gas.

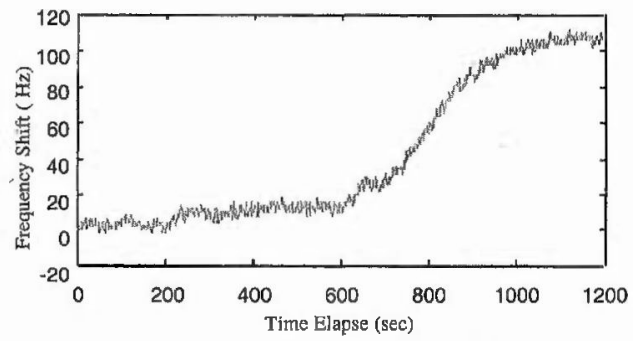

Fig. 6. Frequency shifts of SAW sensor with Carbowax coating for flow tate of $50 \mathrm{cc} / \mathrm{min}$ of nitrogen mixed with $50 \mathrm{cc} / \mathrm{min}$ of test gas.

\subsection{Microwave Cavity Sensor}

Figure 7 shows a schematic diagram of the laboratory setup for testing the MW cavity sensor. To quantify the sensitivity level, the laboratory setup included flow controls and equipment to apply a moderate vacuum. In most experiments, we reached a vacuum level of 0.2 Torr in the cavity. 'Two flow controls were hooked up in tandem to adjust concentrations as needed, with $\mathrm{N}_{2}$ used as the reference gas. 


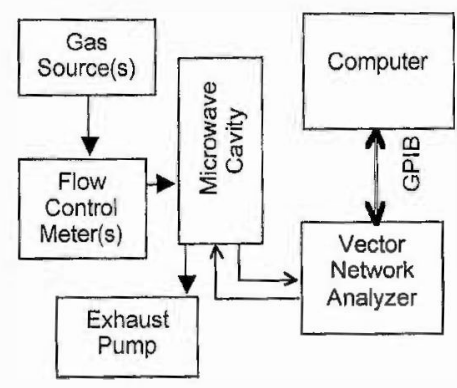

Fig. 7. Equipment layout for testing MW cavity sensor. (GPIB = general purpose interface bus.)

We tested the sensitivity and selectivity of several gases (alcohols, formaldehyde, propylene, ethylene, acetone, water vapor, etc.). Although water vapor does not affect our spectral analysis, it does cause a dielectric shift because of the polar nature of the molecule.

Our next approach was to determine the complex dielectric constant of the experimental gases. The real portion of the dielectric constant $\left(\varepsilon^{\prime}\right)$ is related to the shift in resonance frequencies; the imaginary portion $\left(\varepsilon^{\prime \prime}\right)$ is used to calculate absorption of the peak at that frequency.

Using the quality factor, we can find the dielectric properties of the gas contained in the cavity [10]. The loaded quality factor, $Q_{L}$, is given by $Q_{L}=f_{0} / \Delta f_{f w h h}$. The unloaded quality factor, $Q_{U}$, can then be found by solving the equation $Q_{U}=Q_{L} /\left(1-S_{2 l p}\right)$. Using the unloaded quality

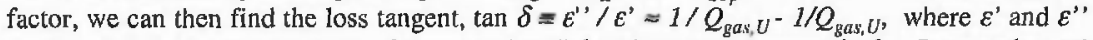
are the real and imaginary parts of the complex dielectric constant respectively. Inasmuch as $\varepsilon^{\prime}$ can be found by solving the equation $\varepsilon^{\prime}=\left(I+\left(f_{\text {evac }}-f_{\text {gas }}\right) / f_{\text {gas }}\right)^{2}$, we now have a means of determining both the real and imaginary parts of the dielectric constant. Because the absorption coefficient is then given by $\alpha=\pi \phi\left(\mu \varepsilon^{\prime}\right)-\tan \delta$, and effective length of a resonator is $L=Q \lambda /$ $2 \pi \quad \approx 20 \mathrm{~m}$ for our cavity), we can calculate the percent absorption from the equation $\%$ $a b$ sorption $=\alpha C L \bullet 100 \%$, where $C$ is the concentration of the gas in question.

We then initiated a series of tests to plot the complex dielectric properties of various gases. Using a bubbler apparatus, we tested the vapor space of various liquids, with nitrogen gas as the flow medium. Figure 8 shows a sampling of the obtained data. The position in the complex plane is shown with fractional concentrations, which can easily be extrapolated to full concentration. These experiments showed high specificity and repeatability for the materials that we tested. 


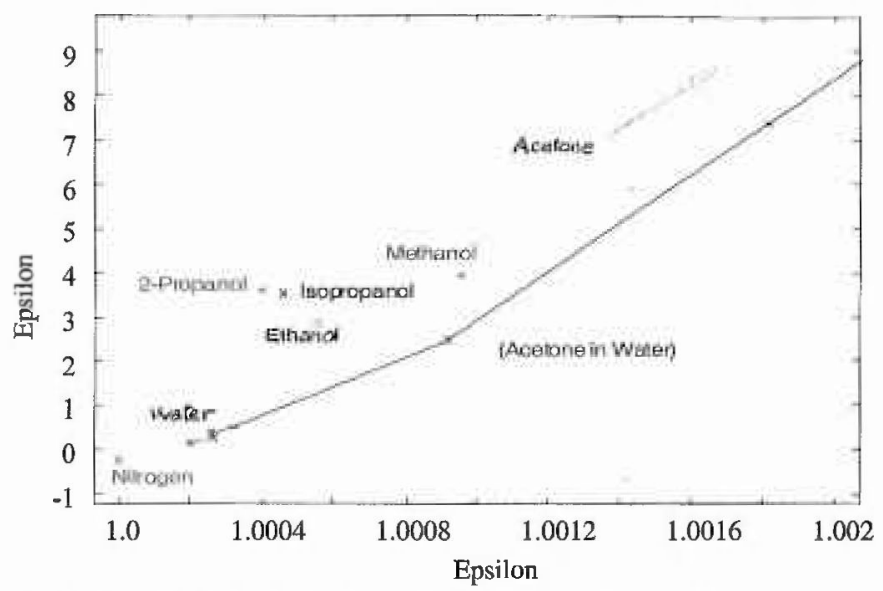

Fig. 8. Sample dielectric data from lab experiments. (All are nitrogen mixtures.)

From the above equations, we can see that $\varepsilon^{\prime}$ is directly related to the induced frequency shift. The change in quality factor, however, is caused by both $\varepsilon^{\prime}$ and $\varepsilon^{\prime \prime}$. This change in quality factor gives a direct method for spectral analysis, whereas the shift in the peak can give the user a sense of the gross change in the system (such as with a moisture sensor); see Fig. 9.
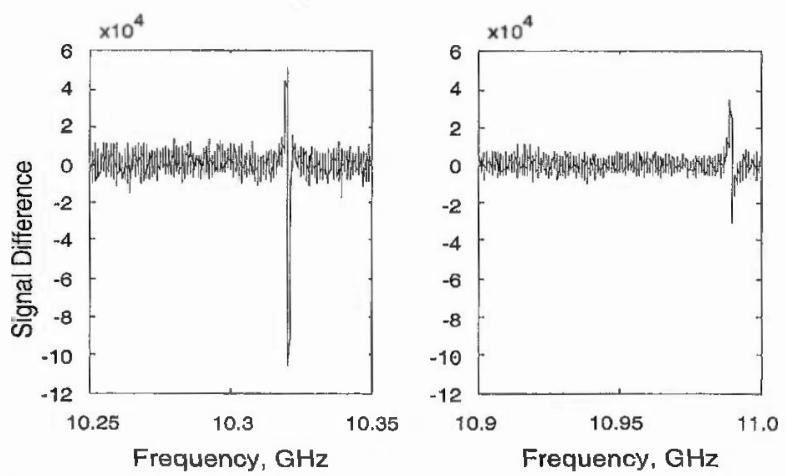

Fig. 9. $0.2 \%$ propylene at various frequencies. $\left(\mathrm{N}_{2}\right.$ reference signal subtracted from gas data.) 
We then performed several experiments on various concentrations of gases. Based on these tests, we concluded that the minimum sensitivity was in the hundreds of parts-per-million (ppm) range for our current cavity setup (Fig. 10).

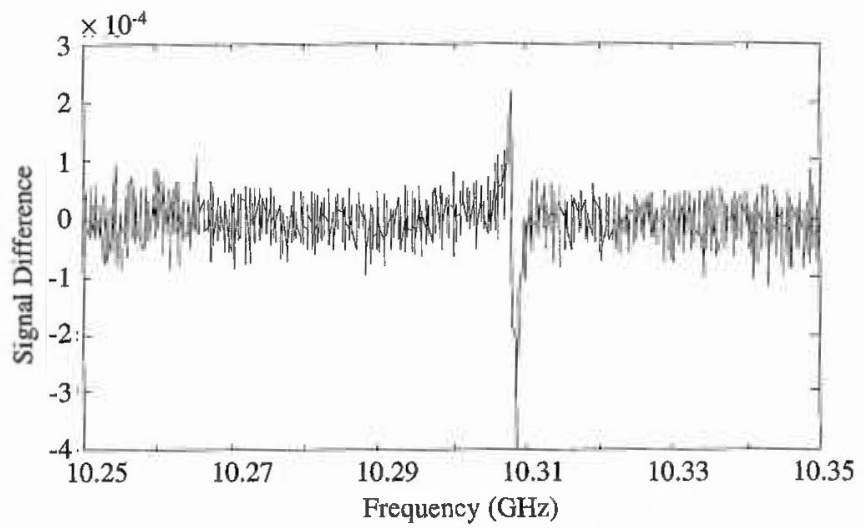

Fig. 10. Sensitivity test using $102 \mathrm{ppm}$ formaldehyde. $\left(\mathrm{N}_{2}\right.$ reference signal subtracted from gas data.)

\subsection{NONRADIOACTIVE ION-MOBILITY SPECTROMETRY SENSOR}

To optimize the performance of exhaust emission systems, future low-emission and high-fuelefficiency vehicles will require a sensor to monitor exhaust line $\mathrm{NO}_{\mathrm{x}}$ emissions. Such a $\mathrm{NO}_{\mathrm{x}}$ sensor must be highly sensitive, exhibit a fast response time $(<1 \mathrm{~s})$, and be able to survive the hostile exhaust environment. An ion-mobility spectrometer has been demonstrated as a low-cost gas sensor [11] that may meet the requirements of an exhaust gas application. Based on ionmolecule chemistry, the basic energy requirement for forming a negative molecular ion is determined by the electron affinity of the molecule. The electron affinities for the negative NO and $\mathrm{NO}_{2}$ ions are $\approx 0.02 \mathrm{eV}$ and $2.3 \mathrm{eV}$, respectively [12]. Therefore, the electron impact ionization process is likely to produce both negative $\mathrm{NO}$ and $\mathrm{NO}_{2}$ ions, but the $\mathrm{NO}_{2}$ ions are thermodynamically more stable. Furthermore, in a plasma, the neutral NO molecule may be oxidized to form $\mathrm{NO}_{2}$, especially in the presence of $\mathrm{HCs}[13,14]$. It is, therefore, possible to estimate the total $\mathrm{NO}_{\mathrm{x}}$ emissions by simply measuring $\mathrm{NO}_{2}$ concentrations. The feasibility of using ${ }^{63} \mathrm{Ni}$-IMS to detect negative $\mathrm{NO}_{2}$ ions has been successfully demonstrated [15]. Because a radioactive source is unacceptable for an automotive application, alternative ionization sources such as corona discharge must be developed. Tabrizchi et al. [16] reported the design of such a pulsed corona-discharge ionization source that is based on a point-to-point geometry. In this work, we describe a pulsed corona-discharge ionization source with a needle-to-cylinder geometry. Preliminary results of its performance in detecting negative $\mathrm{NO}_{2}$ ions are presented. 


\subsection{IMS Sensor Design}

Figure 11 shows the basic design of the IMS sensor. It consists of a pulsed corona discharge ion source, an ion drift tube, and a Faraday plate. The geometry of the ion source assembly is that of a simple needle/metal cylinder. During operation, the metal cylinder is biased with a negative voltage so that negative ions will be confined in the cell until the shutter grid opens. The drift tube of the IMS is a glass tube surrounded by a series of steel guard rings separated by Teflon rings, a configuration that establishes a uniform electrical field for detecting negative ions. Table 3 lists the specific design parameters and typical operating conditions of the IMS sensor.

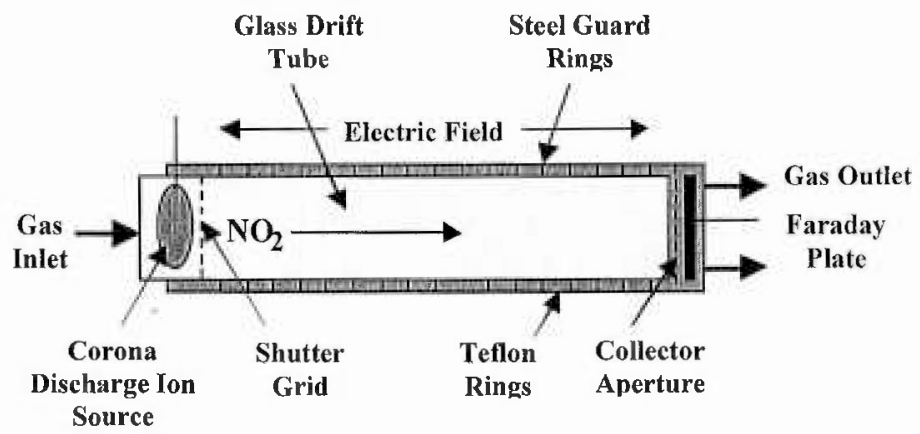

Fig. 11. Basic design of ion-mobility spectrometer.

Table 3. Design parameters and operating conditions of the IMS sensor.

\begin{tabular}{|c|c|c|c|c|c|c|c|c|}
\hline \multicolumn{2}{|c|}{ Ion source } & \multicolumn{3}{|c|}{ Shutter grid } & \multirow{2}{*}{$\begin{array}{c}\text { Drift- } \\
\text { tube } \\
\text { electrical } \\
\text { field, } \\
\mathrm{V} / \mathrm{cm} \\
\end{array}$} & \multicolumn{2}{|c|}{$\begin{array}{c}\text { Detection } \\
\text { Electronics }\end{array}$} & \multirow[b]{2}{*}{$\begin{array}{c}\text { Pressure } \\
\text { and } \\
\text { Temperature }\end{array}$} \\
\hline $\begin{array}{l}\text { Needle- } \\
\text { surface } \\
\text { gap, cm }\end{array}$ & $\begin{array}{c}\text { Applied } \\
\text { voltage, } \\
\mathrm{kV}\end{array}$ & $\begin{array}{c}\text { Pulse } \\
\text { width, } \\
\text { ms }\end{array}$ & $\begin{array}{c}\text { Pulse } \\
\text { voltage, } \\
\text { V } \\
\end{array}$ & $\begin{array}{c}\text { Fre- } \\
\text { quency, } \\
\mathrm{Hz}\end{array}$ & & $\begin{array}{c}\text { Filter, } \\
\mathrm{kHz} \\
\text { (LP) }\end{array}$ & $\begin{array}{l}\text { Sensi- } \\
\text { tivity, } \\
\text { nAN }\end{array}$ & \\
\hline 0.25 & $-3.0 /-4.0$ & 2 & 140 & 12.5 & 220 & 3 & 2 & ambient \\
\hline
\end{tabular}

\subsection{Laboratory Tests}

Laboratory tests were conducted under ambient conditions. Figure 12 shows the experimental setup for testing the IMS. Mass flowmeters (MKS 0-500 sccm) were used to provide the gas mixtures of known $\mathrm{NO}_{2}$ concentration. A water bath and a thermoelectric cooler were incorporated into the carrier-gas line for water vapor tests. Both the sample gas $\left(483 \mathrm{ppm} \mathrm{NO} \mathrm{NO}_{2}\right.$ in dry nitrogen) and carrier gas (23.6 ppm SO $\mathrm{SO}_{2}, 121.2 \mathrm{ppm} \mathrm{H}, 398 \mathrm{ppm} \mathrm{CO}, 8.1 \% \mathrm{O}_{2}, 10 \% \mathrm{CO}_{2}$,

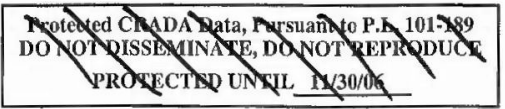


balance, $\mathrm{N}_{2}$ ) are premixed gas mixtures (provided by AGA Gas, Inc.). Because the water content of a typical exhaust gas stream is $\approx 10 \%$, the effect on the IMS sensor due to water must be evaluated. The percent of water vapor in the carrier gas was controlled by varying the temperature of the water bath. The data acquisition system consists of a low-noise, low-current preamplifier (Stanford Research Systems SR570) and a 16-bit, $100 \mathrm{kS} / \mathrm{s}$ digitizer (National Instrument AT-MIO-16E-10). Typically, 100 averages were used for each ion spectrum that was the result of a response time of $80 \mathrm{~ms}$.

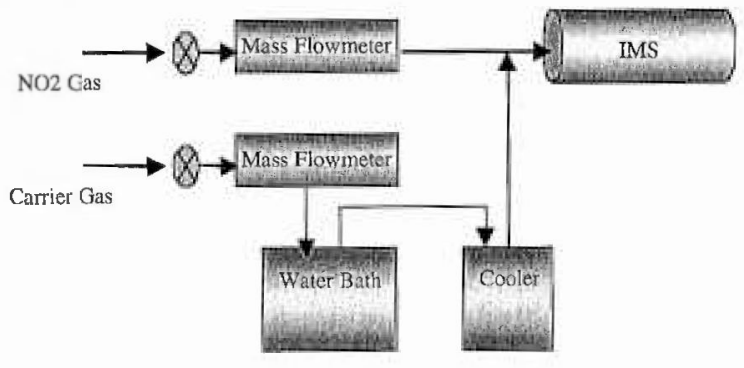

Fig. 12. Schematic diagram of IMS test setup.

Before quantitative tests were performed, both flow rate effect and corona discharge characteristics were examined. Figure 13 shows the effect of gas flow rate on the negative ion spectrum. Slight variations in both amplitude and drift time were measured. The typical flow rate used for the tests was $500 \mathrm{sccm}$. The discharge ionization source could operate in two modes, corona and spark discharge, depending on the applied voltage. The two stages can be easily distinguished from the current measurement, $<0.2 \mathrm{~mA}$ for corona discharge and $>0.5 \mathrm{~mA}$ for spark discharge. A 2-M $\Omega$ resistor was used in series with the ionization source to stabilize the discharge.

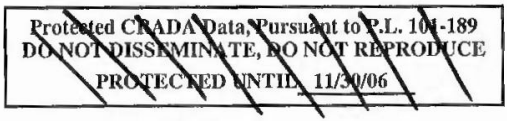




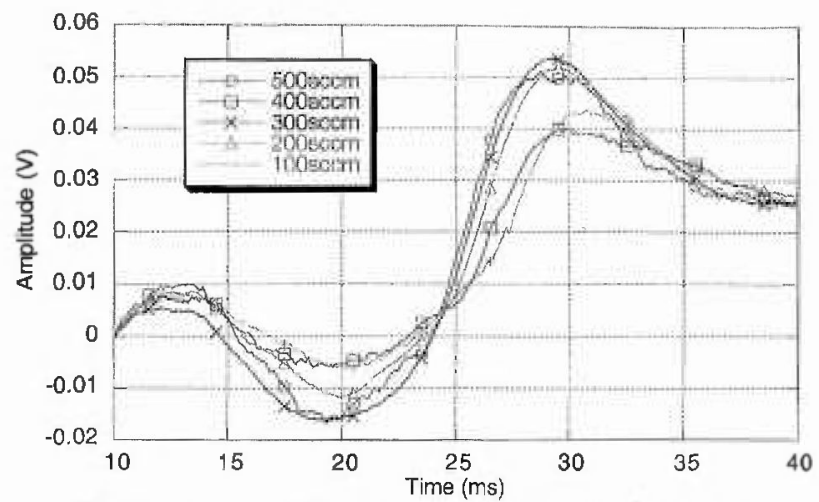

Fig. 13. Negative $\mathrm{NO}_{2}$ ion spectra at various gas flow rates.

\subsection{Results and Discussion}

Figure 14 shows the spectra of a gas mixture with $97 \mathrm{ppm}$ of $\mathrm{NO}_{2}$ in the multicomponent carrier gas, obtained under corona and spark discharge modes. The spark discharge ( $0.8 \mathrm{~mA}$ in current) produces a better-developed peak than does the corona discharge mode $(0.1 \mathrm{~mA}$ in current). Also the drift time between the two spectra differs significantly, which may be due to the difference in ion-molecule chemistry or the type of ions produced. Figure 15 shows the corona discharge spectra for four gas mixtures $\left(\mathrm{NO}_{2} / \mathrm{N}_{2}\right.$ and carrier gas) with differing concentrations of $\mathrm{NO}_{2}$. The data show that as $\mathrm{NO}_{2}$ concentration increases, the ion peak decreases in amplitude but increases in drift time.

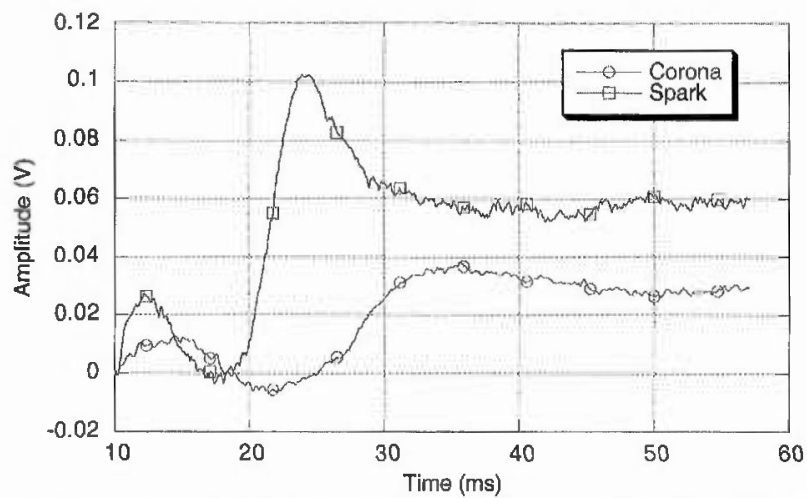

Fig. 14. Negative $\mathrm{NO}_{2}$ ion spectra produced by corona and spark discharges.

ProtectedCRAMA Data, Pursyant toP.L. N1-189 DQ NQT DKSEMYNAT DO NOT RTPROLUCE PROTKCTE UNTIL 11>30/06 


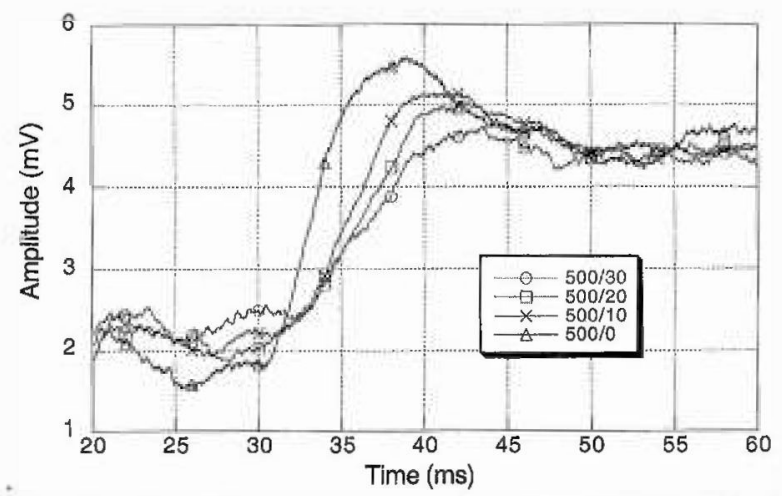

Fig. 15. Negative $\mathrm{NO}_{2}$ inn peaks produced by corona discharge ionization for four gas mixtures with differing concentrations of $\mathrm{NO}_{2}$.

It was also noticed that the current flowing through the ion source decreased with the peak amplitude, indicating that fewer ions were generated. Furthermore, an ion peak was detected when only carrier gas was introduced. This result suggests that, under the corona discharge mode, the primary negative ion produced may be $\mathrm{O}_{2}^{-}$and introduction of $\mathrm{NO}_{2}$ reduces the $\mathrm{O}_{2}^{-}$. The trend for the spark discharge mode differed, as may be seen in Fig. 16. An increase of peak amplitude was observed with the increase of $\mathrm{NO}_{2}$ concentration, but the drift time remained relatively unchanged, a finding that suggests that the spark discharge mode of operation may be used to quantify the $\mathrm{NO}_{2}$ concentration by measuring the peak amplitude.

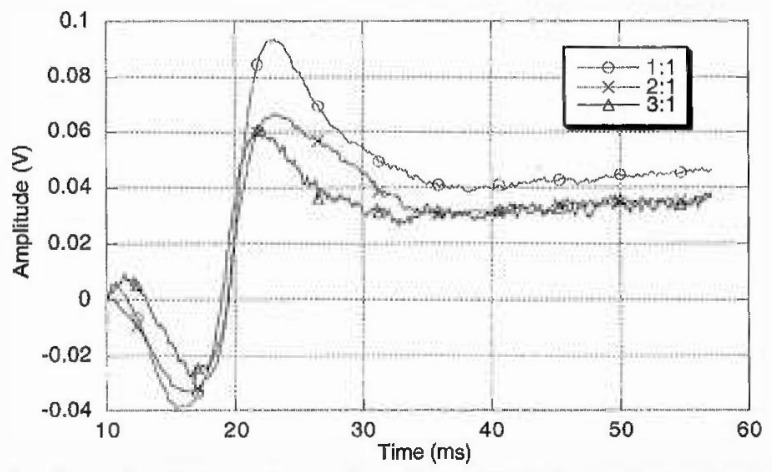

Fig. 16. Negative $\mathrm{NO}_{2}$ spectra produced by spark discharge ionization for three $\mathrm{NO}_{2}$ concentrations expressed in terms of the carrier/sample gas ratio.

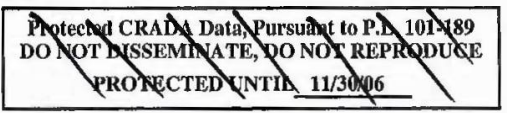


Figure 17 shows the dependence of peak amplitude on $\mathrm{NO}_{2}$ concentration up to $500 \mathrm{ppm}$ of $\mathrm{NO}_{2} / \mathrm{N}_{2}$ gas mixture. The dependence of amplitude on concentration was also measured, as shown in Fig. 18, for $\mathrm{NO}_{2}$ /carrier-gas mixtures. Quantitatively, the $\mathrm{NO}_{2}$ /carrier-gas mixture produces more ions than the $\mathrm{NO}_{2} / \mathrm{N}_{2}$ gas mixture. Without introducing $\mathrm{NO}_{2}$ gas, the carrier gas mixture shows an ion peak of significant magnitude with a delay time in the region where the $\mathrm{NO}_{2}$ ions appear (14.5-16 ms). This result suggests that $\mathrm{NO}_{2}$ may be produced in the plasma during the spark discharge process if the composition of the buffer gas is the same as that of the carrier gas. It is possible that the presence of oxygen $(8.1 \%)$ in the carrier gas induces the reactions that lead to the production of $\mathrm{NO}_{2}$ ions.

The presence of water vapor in IMS tends to degrade the ion spectrum. Figure 19 shows the extent of degradation of the $\mathrm{NO}_{2}$ ion spectra of the gas mixtures that contain various concentrations of water vapor. In most cases, we found that the ion spectrum was completely masked by noise when the vapor content exceeded $1 \%$. Therefore, a method to reduce the noise is necessary for practical applications. We investigated a cooling method that condenses water vapor before the gas enters the IMS. Figure 20 shows three ion spectra obtained when vaporsaturated gas passed through a cooling bath adjusted to the indicated temperatures. The spectra show that, as temperature decreases, the signal-to-noise ratio improves and the delay time of the peak decreases. The changes in delay time suggest that the size of water clusters may be reduced as the temperature decreases. With the gas flowing through the cold plate before entering the IMS, we enable the recovery of the ion spectra. Figure 21 shows the dependence of the peak amplitude on concentration with the gas kept at $0^{\circ} \mathrm{C}$

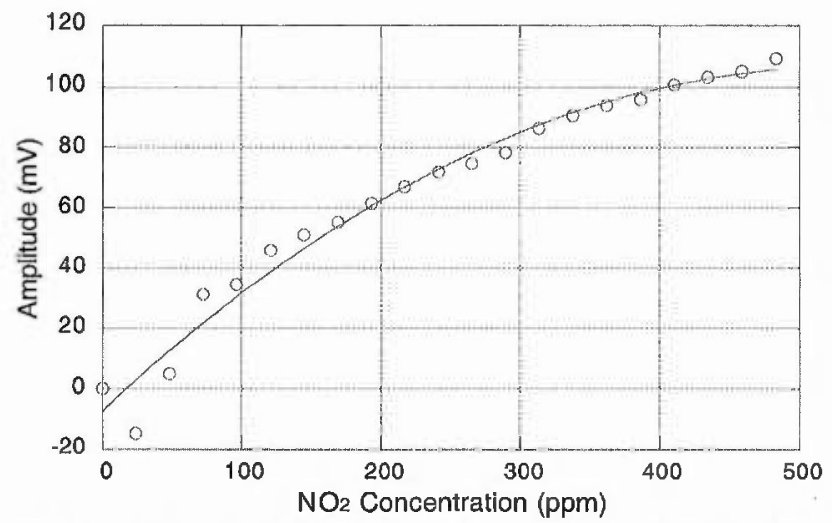

Fig. 17. Peak amplitude vs. $\mathrm{NO}_{2}$ concentration, measured with dry nitrogen and $2-n A / V$ sensitivity.

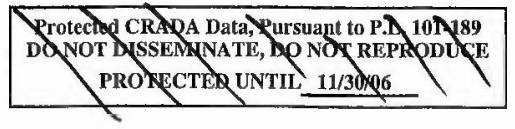




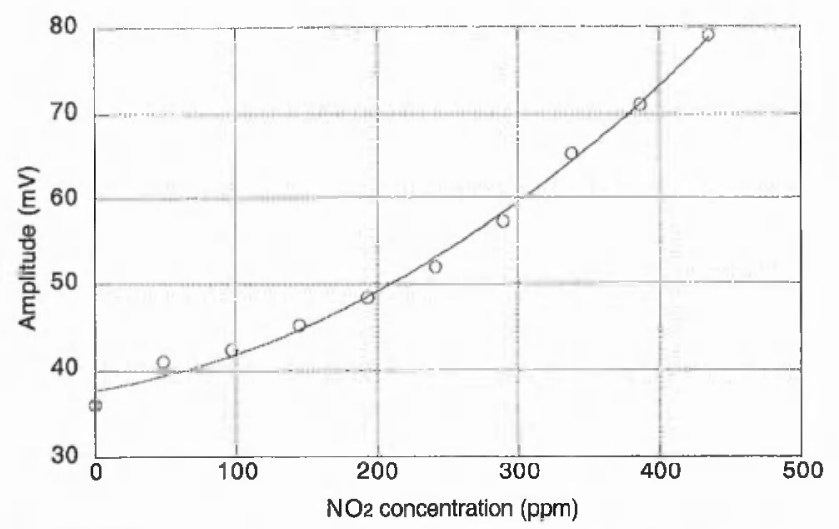

Fig. 18. Peak amplitude vs. $\mathrm{NO}_{2}$ concentration measured with carrier gas and 5-nA/V sensitivity.

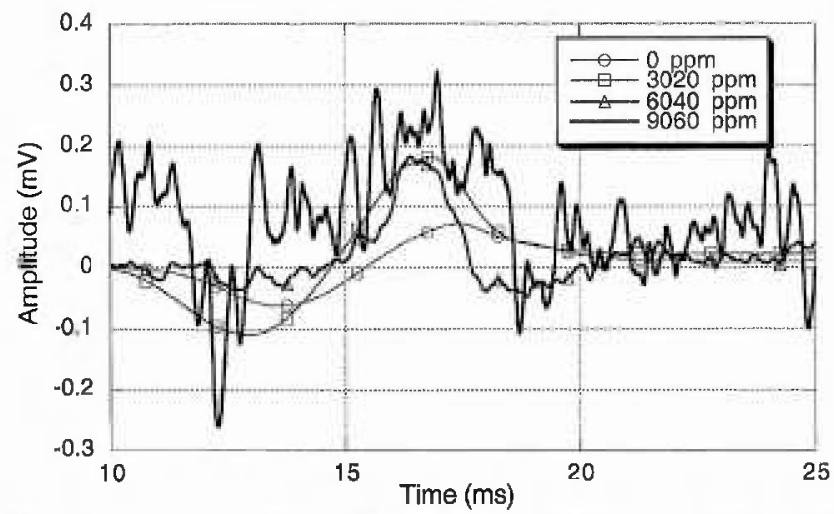

Fig. 19. $\mathrm{NO}_{2}$ ion spectra of $\mathrm{NO}_{2}$ /carrier-gas mixtures with various water vapor concentrations.

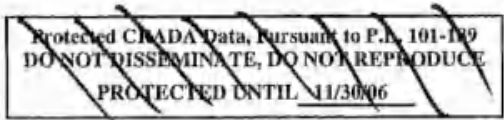




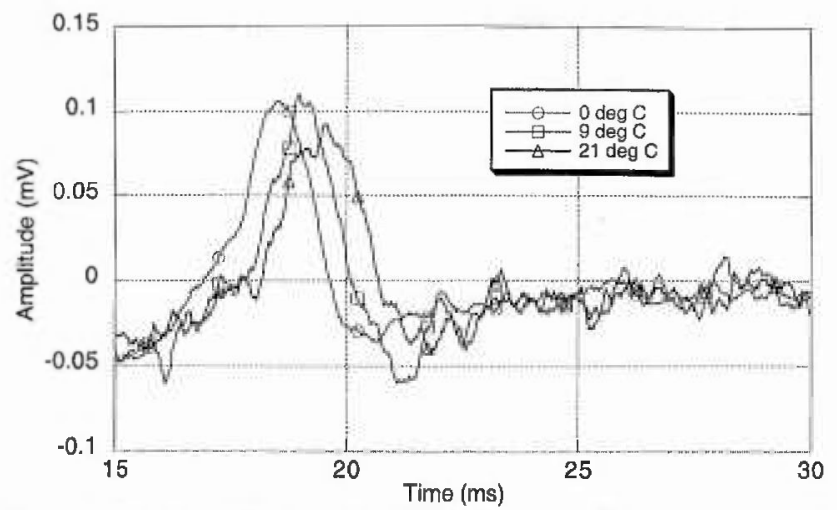

Fig. 20. Negative $\mathrm{NO}_{2}$ ion peaks detected by controlling carrier gas temperature.

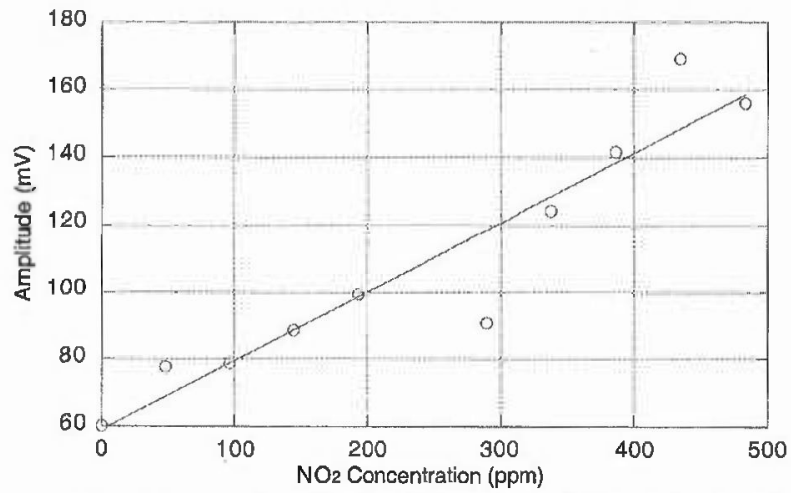

Fig. 21. Amplitude of negative $\mathrm{NO}_{2}$ ion peak vs. gas concentration with temperature controlled at $0^{\circ} \mathrm{C}(2-\mathrm{nA} / \mathrm{V}$ sensitivity).

\subsection{CONCLUSIONS}

Under this CRADA project, we have evaluated acoustic, microwave, and IMS technologies, for potential applications to tailpipe emissions monitoring. Because the environment in the exhaust stream is hostile, only the IMS sensor may be applicable. However, the radioactive ion source commonly used in IMS is not acceptable. Thus, later in this project, the focus was placed on development of a nonradioactive ion source. We have demonstrated that a spark discharge ion

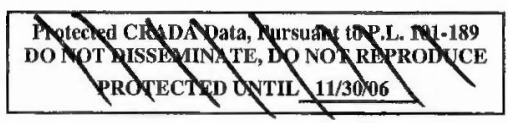


source can be used to replace the radioactive source. Positive results for detecting $\mathrm{NO}_{2}$ are presented.

The evaluated acoustic technologies include SAW and FPW microsensors. The main difficulty with these sensors is the selection of $\mathrm{NO}_{\mathrm{x}} / \mathrm{HC}$-sensitive coatings that can survive in the hightemperature exhaust environment. The coatings that were tested under ambient conditions show rather poor sensitivity and stability. Thus, under the present term of the CRADA, a reliable and sensitive $\mathrm{SAW} / \mathrm{FPW}$ sensor for detecting $\mathrm{NO}_{\mathrm{x}} / \mathrm{HCs}$ could not be developed.

The microwave technique, when applied to emission monitoring, is based on measuring resonance frequency in a MW cavity. The laboratory tests have shown that the idea of a complex plane representation of the dielectric constants at atmospheric pressure is attractive for onboard measurements. Furthermore, the complex dielectric approach reduces the need for moderate vacuum requirements. Thus, the MW cavity resonance technique can be applied to measurements of chemicals with dipole moments, and although it proved effective for measuring gross change in emissions patterns, the $\varepsilon$ ' effect appeared more pronounced than the $\varepsilon$ " effect. This effect, and the polar nature of water molecules, means that this cavity can also be made into a very sensitive moisture detector. The main limitation of the MW cavity technique is the quality factor. Ways to improve this include coating the interior of the cavity with a better conductor to improve waveguide performance, and machining parts for greater precision and better cavity response. At present, the cost of the cavity and control electronics may not be attractive.

We describe a practical $\mathrm{NO}_{2}$ sensor based on the IMS technique. The sensor uses a nonradioactive ionization source, operates under ambient conditions, detects negative $\mathrm{NO}_{2}$ ions, and has a response time of $80 \mathrm{~ms}$. The configuration of the nonradioactive ionization source is a simple needie-metal-cylinder geometry that allows either corona or spark discharge to develop in the gap between the needle and the cylinder. Preliminary results show that the spark-discharge mode of operation can be used to quantify $\mathrm{NO}_{2}$ concentration.

Although we have demonstrated the feasibility of detecting $\mathrm{NO}_{2}$ by the IMS technique, with a pulsed spark discharge ion source, a few technical hurdles must be overcome before an IMS sensor can be used in an exhaust environment. These hurdles include (a) effects due to water vapor, (b) drift time ambiguity, and (c) complexity of the ion-molecule chemistry due to variations of the exhaust gas composition. The water vapor effect has already been examined. Without pretreatment of the gas, the ion spectrum is completely masked by noise when the water content exceeds $1 \%$. A thermoelectric cold plate was used to condense water from the gas stream before entering the IMS. Efforts to reduce the water effect produced positive results.

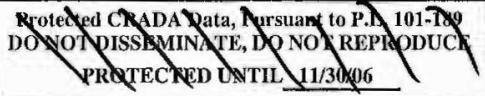


1. R. M. White and F. W. Voltmer, "On waves propagated along the plane surface of a solid," Appl. Phys. Lett., 7, pp. 314-316, 1965.

2. R. M. White, "Surface acoustic wave sensors," Proc. IEEE, Ultrasonics Symp., pp. 490$494,1985$.

3. H. Wohltjen and R. E. Dessy, "Surface acoustic wave probe for chemical analysis, II: Gas chromatography detector," Anal. Chem., 51(9), pp. 1458-1464, 1979.

4. S. W. Wenzel and R. M. White, "Analytic comparison of the sensitivities of bulk-wave, surface-wave, and flexural plate-wave ultrasonic gravimetric sensors," Appl. Phys. Lett. 54(20), pp. 1976-1978, 1989.

5. S. W. Wenzel and R. M. White, "Flexural plate-wave sensor: chemical vapor sensing and electrostrictive excitation," Proc. IEEE, Ultrasonics Symp., pp. 595-598, 1989.

6. A. Balanis, Advanced Engineering Electromagnetics, John Wiley \& Sons, New York, 1989.

7. E. A. Mason, "Ion mobility: Its role in plasma chromatography," Chapter 2 in Plasma Chromatography, Plenum Press, New York, 1984.

8. M. A. Biondi and L. M. Chanin, "Blanc's law - jon mobilities in helium-neon mixtures," Phys. Rev. 122, pp. 843-847, 1961.

9. J. A. Jendrzejczyk, S. L. Dieckman, S. Slaughter, and A. C. Raptis, "Response of a prototype vehicle exhaust gas sensor to various hydrocarbons and other constituents," Argonne National Laboratory report, ANL-99/5, 1999.

10. J. A. Jendrzejczyk, S. L. Dieckman, S. Slaughter, and A. C. Raptis, "Response of a prototype vehicle exhaust gas $\mathrm{NO}_{\mathrm{x}}$ sensor to various hydrocarbons and other constituents," Argonne National Laboratory report, ANL-99/19, 1999.

11. A. F. Harvey, Microwave Engineering, Academic Press, New York, 1963.

12. G. A. Eiceman and Z. Karpas, Ion-Mobility Spectrometry, CRC Press, Boca Raton, FL, 1994.

13. B. M. Smimov, Negative lons, McGraw-Hill Inc., New York, pp. 27-31, 1982.

14. B. M. Penetrante, W. J. Pitz, M. C. Hsiao, B. T. Merritt, and G. E. Vogtlin, "Effect of hydrocarbons on plasma treatment of $\mathrm{NO}_{x}$," Proceedings of the 1997 Diesel Engine Emissions Research Workshop, San Diego, CA, July 28-31, 1997, pp. 123-128.

15. S. G. Ejakov, H.-T. Chien, R. Dorai, J. A. Jendrzejczyk, A. C. Raptis, S.-H. Sheen, and J. $\mathrm{H}$. Visser, "Modeling the Use of a Plasma Source in Ton Mobility Spectrometry for $\mathrm{NO}_{\mathrm{x}}$ Detection in Automotive Exhaust," ISIMS - 2001, Wernigerode, Germany, August 12-17, 2001.

16. M. Tabrizchi, T. Khayamian, and N. Taj, "Design and operation of a corona discharge ionization source for ion-mobility spectrometry," Rev. Sci. Inst. Vol. 71 (6), pp. 2321$2328,2000$. 


\section{Distribution for ANL-01/27}

Internal

$\begin{array}{lll}\text { J. L. Carlson (2) } & \text { L. Johnson } & \text { S.-H. Sheen (15) } \\ \text { H.-T. Chien (10) } & \text { J. Harmon } & \text { R. A. Valentin } \\ \text { H. Drucker } & \text { R. B. Poeppel } & \text { TIS Files } \\ \text { N. Gopalsami (10) } & \text { A. C. Raptis } & \\ \text { J. A. Jendrzejczyk } & \text { W. Schertz } & \end{array}$

External

U.S. Department of Energy

Office of Transportation

R. Sullivan

DaimlerChrysler

$$
\text { A. Lee }
$$

Ford Motor Company

D. Kubinski

K. Nietering

M. Parsons

R. Soltis

J. Sorab

J. Visser

GM Milford Proving Grounds

F. Ament

G. Gonze

S. Schmieg

Energy Technology Division Review Committee

H. K. Birnbaum, University of Illinois at Urbana-Champaign

I.-W. Chen, University of Pennsylvania

F. P. Ford, Rexford, NY

S. L. Rhode, University of Nebraska - Lincoln

H. S. Rosenbaum, Fremont, CA

S. L. Sass, Cornell University

R. Zoughi, University of Missouri-Rolla 